\title{
District programme to reduce smoking: can sustained intervention by general practitioners affect prevalence?
}

\author{
M A H RUSSELL, ${ }^{1}$ J A STAPLETON, ${ }^{1}$ P HAJEK, ${ }^{1}$ P H JACKSON, ${ }^{1}$ AND M BELCHER ${ }^{2}$ \\ From the Addiction Research Unit, ${ }^{1}$ Institute of Psychiatry, London SE5 8AF; and Smokers Clinic, ${ }^{2}$ Maudsley \\ Hospital, London SE5 8AZ
}

SUMMARY A total of 101 general practitioners in 27 practices in inner London took part in a quasi-experimental study designed to examine whether a brief intervention applied to all smokers seen by general practitioners and sustained on a continuous basis could in time have a cumulative effect and reduce the prevalence of smoking among their patients. Of 21 practices approached in our local district (Camberwell), seven were willing to undertake brief intervention with support from the smokers' clinic (SBI), four opted for intervention without support (BI), and six acted as usual care controls. A further 10 out of 12 practices approached in South Hammersmith provided an unselected group of usual care controls. A series of six cross-sectional surveys were conducted over a three-year period. Each survey consisted of all adult patients attending to see a doctor during a defined two-week period, sample sizes averaging just over 9000 per survey. The estimated decline in self-reported smoking prevalence over the 30-month period following the start of intervention was $5.5 \%$ (from $36.4 \%$ to $30.9 \%$ ) in the SBI group compared with $2.1 \%$ for BI and $2.8 \%$ and $3.0 \%$ in the two usual care control groups, the decline in the SBI group being significantly greater than in the other groups which did not differ significantly between each other. These interim results provide encouraging evidence that brief intervention by general practitioners with support and back-up from a local smokers' clinic can, when sustained on a continuous basis, reach sufficient smokers to reduce smoking prevalence in their practice populations. However, firm conclusions must await longer periods of observation now that the other Camberwell practices have adopted the SBI procedures.

Brief intervention by general practitioners (GPs) is effective in motivating and helping people to give up smoking, ${ }^{1-4}$ and more intensive GP intervention can achieve success rates comparable with those of specialised smokers' clinics. ${ }^{5-6}$ Previous studies have reported the effect of intervention in limited groups of patients recruited during three to four week recruitment periods after which the GPs were free to resume their usual care with patients not in the study.

Although more demanding, it is obviously desirable that a procedure of proven efficacy should as far as possible be incorporated into the daily routine care of patients on a continuous basis, rather than as a transient intrusive element undertaken for the purposes of a given study. As some $75 \%$ of patients attend their GPs surgeries over the course of each year, it follows that any intervention procedure practised by GPs on a routine basis would within a few years reach most of the smokers on their practice lists at least once and in most cases several times. It is therefore possible that such routine intervention could in time have a cumulative effect and produce a measurable and worthwhile decline in the prevalence of smoking in the practice population. It follows further that if a sufficiently high proportion of GPs could be encouraged and supported to undertake brief intervention on a routine basis, their collective effort could add significantly to the effect of other approaches aimed at reducing smoking at a national level.

The purpose of the overall programme is to explore and evaluate the extent to which a smokers' clinic can mobilise, support, and co-ordinate intervention by GPs and other health professionals in a Health Authority District and to see whether this could in time produce a detectable decline in the prevalence of smoking in the whole community of the District, insofar as it is represented by those registered on the lists of the District's GPs. The first phase of the programme has involved developing an effective package to facilitate and support brief intervention by GPs, and the results of a one year prospective study of two brief intervention procedures are reported elsewhere. ${ }^{4}$ Another purpose of the first phase was to 
set up a system of periodic cross-sectional surveys for long-term monitoring of smoking prevalence among GPs' patients in the local District of our smokers' clinic (Camberwell) and a control District (South Hammersmith).

Six surveys have been completed so far and include two base-line surveys and four surveys covering the first 30 months after the start of GP intervention. The GPs were encouraged to sustain their intervention throughout this period and to apply it as far as possible to all smokers who attend. Although this first phase has been concerned more with the development of an effective GP intervention for long-term application, the results at this stage are presented as an interim report on the cumulative effect of GP intervention on the prevalence of smoking among their patients when the intervention is sustained on a continuous basis.

\section{Subjects and methods}

\section{INTER VENTION PROCEDURES}

Two brief intervention procedures were tested. Both involved the doctors in noting the smoking habits of all adult patients attending their surgeries, advising all cigarette smokers to stop, giving them a leaflet about smoking and how to give it up, and offering nicotine chewing gum (on private prescription) to those who anticipated difficulty in stopping. Those who accepted the gum were also given a manufacturer's booklet explaining how it should be used. In the practices doing brief intervention (BI) without clinic support, the doctors recorded smoking status in their own hand-writing in the patients' notes and received no ongoing support and back-up from the smokers' clinic. The supported brief intervention (SBI) involved, in addition, the provision of special smoker/ non-smoker labels for the patients' notes with space for follow-up attendances, a leaflet about the smokers' clinics available in the district, and reply paid postal referral cards to the clinic of their choice, together with a series of five brightly coloured posters about the risks of smoking for use in the waiting rooms. In both cases the materials and appropriate guidance for the doctors were put together in convenient folders to be kept on the doctors' desks. Further details of the intervention procedures are described elsewhere. ${ }^{4}$

\section{RECRUITMENT OF GPS}

We approached all practices in the Camberwell District having three or more partners as well as the two largest practices with two partners, and one single-handed practice which shared a health centre with other participating practices. Out of 21 practices, seven were willing to undertake the SBI procedure on a continuous basis, four opted for BI, six were not willing to do routine intervention but agreed to act as usual care (UC) controls, and four were unable to participate in any way. A further 12 practices in South Hammersmith were asked to participate as UC controls and 10 of them were willing to do this. Although a little smaller than Camberwell in population, South Hammersmith was selected as the control District in view of the similarity of its population in the proportion of those aged over 65 years and its similar infant mortality (an index of social class).

There were 101 doctors in the 27 practices who took part in the study, together with their locums and assistants. In most cases the few practices unable to take part gave good reasons for this. No attempt was made to select the better organised practices or those with an interest in research. The practices were therefore fairly typical inner London group practices, although single and two-handed practices were underrepresented. Because only seven Camberwell practices were willing to undertake the SBI procedure, random allocation was not possible and the assignment to intervention and control procedures was determined by self-selection. However, the practices in South Hammersmith provided a substantial group of unselected UC controls.

\section{PREVALENCE SURVEYS}

These involved the administration of a brief selfcompletion questionnaire to all adult patients aged 16 or more attending the surgeries to see a doctor during a defined two-week period. As an economy, and to keep the procedures as "natural" as possible, they were conducted by the GPs' receptionists rather than hired interviewers. Despite careful briefing and written instructions, in the early stages some receptionists were inconsistent about giving the questionnaire to all eligible patients. However, this does not appear to have biased the results. In one initially lax practice the results were no different when a research assistant administered the questionnaire for a three-day period. The receptionists did not comply to the extent of keeping accurate data on non-respondents and usually claimed that there were none. In this setting it is rare for patients to refuse to fill in a brief questionnaire. In a previous study only $3.2 \%$ of patients were unwilling, unable or did not have time to complete a questionnaire. $^{3}$

The questionnaire consisted of a one-page "smoking record card". Apart from details of name, age, sex, and occupation, it contained four questions on past and present smoking habits and could be completed by most patients within two to three minutes. The receptionists filled it in for patients who had problems such as poor sight or reading difficulties. 
Table 1 Demographic characteristics and cigarette smoking habits of patients attending the surgeries of intervention and control practices as shown by merging the two surveys which preceded the start of intervention.

\begin{tabular}{|c|c|c|c|c|}
\hline & \multicolumn{2}{|c|}{ Usual care controls } & \multirow{2}{*}{$\begin{array}{l}\text { Brief } \\
\text { intervention } \\
\text { (4 practices) }\end{array}$} & \multirow{2}{*}{$\begin{array}{l}\text { Supported } \\
\text { brief } \\
\text { intervention } \\
\text { (7 practices) }\end{array}$} \\
\hline & $\begin{array}{l}\text { Hammersmith } \\
\text { (10 practices) }\end{array}$ & $\begin{array}{l}\text { Camberwell } \\
\text { (6 practices) }\end{array}$ & & \\
\hline Number of patients & 6500 & 3122 & 3018 & 5097 \\
\hline Mean age (yr) & $\begin{array}{l}42.5 \\
\text { (SD 17.9) }\end{array}$ & $\begin{array}{l}44.9 \\
\text { (SD 18.5) }\end{array}$ & $\begin{array}{l}42.9 \\
\text { (SD 19.0) }\end{array}$ & $\begin{array}{l}45 \cdot 2 \\
\text { (SD 18.1) }\end{array}$ \\
\hline$\%$ Women & $65 \cdot 3$ & 63.8 & $66 \cdot 6$ & $66 \cdot 1$ \\
\hline \% Social class I \& II & 19.8 & 10.8 & 18.4 & 19.5 \\
\hline $\begin{array}{l}\text { Cigarette smoking } \\
\text { Never smoked (\%) }\end{array}$ & $34 \cdot 0$ & 33.8 & $38 \cdot 6$ & $38 \cdot 0$ \\
\hline Ex-smoker (\%) & $24 \cdot 3$ & $23 \cdot 5$ & $23 \cdot 0$ & $25 \cdot 6$ \\
\hline Smoker (\%) & $41 \cdot 7$ & $42 \cdot 7$ & $38 \cdot 4$ & $36 \cdot 4$ \\
\hline $\begin{array}{l}\text { Mean number of } \\
\text { cigarettes/day }\end{array}$ & $\begin{array}{l}17 \cdot 2 \\
\text { (SD 10.6) }\end{array}$ & $\begin{array}{l}17 \cdot 4 \\
\text { (SD 10.7) }\end{array}$ & $\begin{array}{l}16 \cdot 2 \\
\text { (SD 10.1) }\end{array}$ & $\begin{array}{l}16.6 \\
\text { (SD 10.1) }\end{array}$ \\
\hline
\end{tabular}

Note: All practices in the two intervention groups were in the Camberwell District.

The surveys were run simultaneously in all 27 practices during two-week periods in May or October. Six surveys have been done so far, each one totalling about 9000 patients. The two base-line surveys were run in May and October 1982. The intervention started immediately after the second survey in October 1982 and was kept up throughout the subsequent 30 months, further surveys being run in May 1983, October 1983, October 1984, and May 1985. Patients who reattended were not included twice in the same survey, but it was possible for a patient to be included in several different surveys.

All statistical analyses were carried out using the GLIM or SAS statistical packages. ${ }^{78}$ The one-sided hypothesis that increasing levels of intervention would result in greater declines in smoking prevalence was tested.

\section{Results}

Table 1 shows the baseline demographic characteristics and cigarette smoking habits of patients in the different practice groups before the start of intervention. The proportion of women did not differ significantly between the four practice groups, but there were significant differences in age $(p<0.001)$, social class $(p<0.001)$, cigarette consumption $(p<0.001)$, and the base-line prevalence of cigarette smoking $(p<0.001)$. Within the Camberwell Groups there was a significant tendency for the prevalence of smoking to be lower among patients from the practices that were more willing to undertake intervention $(p<0.005)$.

The changes in the prevalence of cigarette smoking nine months and 27 months after the start of intervention are shown in table 2 . In view of the differences between the practice groups in baseline smoking habits and demographic characteristics, direct comparisons of the unadjusted data could be misleading. To allow for these factors and for practice differences within practice groups and the selfselection of practices to intervention or control groups, a full logistic linear model was fitted to examine the prevalence trends over time and included significant terms for practices, age, sex, social class, and their interactions. No seasonal effect on smoking prevalence was observed after these terms had been fitted, but there was a significant interaction between age of patients and the linear time trend over the period of the surveys, older patients being more likely to give up smoking $\left(\chi^{2}=13.0, \mathrm{df}=1, \mathrm{p}<0.001\right)$. There were no such effects for sex or social class, nor was there any evidence of a quadratic component in the time trend $\left(\chi^{2}=0.1\right)$.

As shown in table 2, there was a significant decline in the prevalence of cigarette smoking in the two UC control groups and in the patients of the SBI practices, but the change was not statistically significant in the case of the BI practices. The decline in the usual care groups was consistent with the national trend over the period which showed a reduction in cigarette smoking prevalence from $35 \%$ in 1982 to $34 \%$ in 1984.9 However, the decline in the SBI group was significantly greater than that of the other three groups when compared individually $\left(\chi^{2}=3.1,3.5\right.$, 4.2 , df $1, \mathrm{p}<0.05)$ or in combination $\left(\chi^{2}=6.0\right.$, df 1 , $\mathrm{p}<0.025)$, and none of the differences between the other three groups was statistically significant. As the figure shows, the linear time trend of the decline in prevalence of smoking did not differ between the BI and control groups but the rate of decline was significantly greater among patients 
Table 2 Changes in smoking prevalence among patients attending GPs' surgeries between May 1982 and May 1985. Values shown are the percentage of cigarette smokers with the number of patients surveyed in parentheses.

\begin{tabular}{|c|c|c|c|c|}
\hline & \multicolumn{2}{|c|}{ Usual care controls } & \multirow{2}{*}{$\begin{array}{l}\text { Brief } \\
\text { intervention } \\
\text { (4 practices) }\end{array}$} & \multirow{2}{*}{$\begin{array}{l}\text { Supported } \\
\text { brief } \\
\text { intervention } \\
\text { (7 practices) }\end{array}$} \\
\hline & $\begin{array}{l}\text { Hammersmith } \\
\text { (10 practices) }\end{array}$ & $\begin{array}{l}\text { Camberwell } \\
\text { (6 practices) }\end{array}$ & & \\
\hline $\begin{array}{l}\text { Pre-intervention } \\
\text { (May } 82 \text { + Oct 82) }\end{array}$ & $\begin{array}{l}41 \cdot 7 \% \\
(n=6500)\end{array}$ & $\begin{array}{l}42 \cdot 7 \% \\
(n=3122)\end{array}$ & $\begin{array}{l}38 \cdot 4 \% \\
(n=3018)\end{array}$ & $\begin{array}{l}36 \cdot 4 \% \\
(n=5097)\end{array}$ \\
\hline $\begin{array}{l}\text { After } 9 \text { months' intervention } \\
\text { (May } 83+\text { Oct } 83 \text { ) }\end{array}$ & $\begin{array}{l}40.8 \% \\
(n=7409)\end{array}$ & $\begin{array}{l}40 \cdot 1 \% \\
(n=3272)\end{array}$ & $\begin{array}{l}35 \cdot 8 \% \\
(n=2461)\end{array}$ & $\begin{array}{l}33 \cdot 2 \% \\
(n=5091)\end{array}$ \\
\hline $\begin{array}{l}\text { After } 27 \text { months' intervention } \\
\text { (Oct } 84+\text { May 85) }\end{array}$ & $\begin{array}{l}39 \cdot 7 \% \\
(n=7628)\end{array}$ & $\begin{array}{l}39.4 \% \\
(n=2964)\end{array}$ & $\begin{array}{l}33 \cdot 9 \% \\
(n=2488)\end{array}$ & $\begin{array}{l}32.0 \% \\
(n=5444)\end{array}$ \\
\hline $\begin{array}{l}\text { Change over survey period } \\
\text { Unadjusted }\end{array}$ & $-2 \cdot 0$ & $-3 \cdot 3$ & -4.5 & $-4 \cdot 4$ \\
\hline $\begin{array}{l}\text { Adjusted } \\
(95 \% \mathrm{CI})\end{array}$ & $\begin{array}{l}-3 \cdot 0 \\
(-4 \cdot 8,-1 \cdot 3)\end{array}$ & $\begin{array}{l}-2 \cdot 8 \\
(-5 \cdot 6,0 \cdot 0)\end{array}$ & $\begin{array}{l}-2 \cdot 1 \\
(-5 \cdot 1,0 \cdot 0)\end{array}$ & $\begin{array}{l}-5 \cdot 5 \\
(-7 \cdot 4,-3 \cdot 6)\end{array}$ \\
\hline$\chi^{2} L$ & 11.0 & 3.6 & 2.0 & 28.7 \\
\hline$p$ value & $<0.005$ & $<0.05$ & $<0.1$ & $<0.0001$ \\
\hline
\end{tabular}

Note: Data from the six surveys are shown merged as three pairs, the survey dates of each pair being shown in parentheses. The percentages shown are unadjusted, but the statistical tests are based on the logistic linear model over all six surveys with adjustments for significant covariates: age, sex, social class, and practices. The estimated changes in prevalence after these adjustments are also shown.

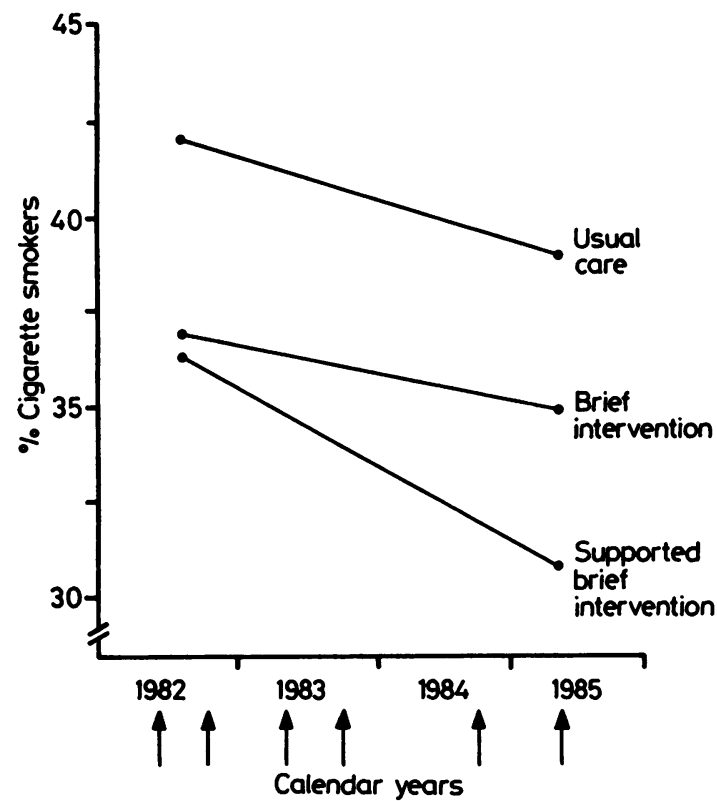

Logistic linear regressions of prevalence over time after adjusting for age, sex, social class, and practice effects. The rate of decline in the $S B I$ group was significantly greater than that of the UC controls $\left(\chi^{2}=4.9, p<0.025\right)$ and the BI group $\left(x^{2}=3.5, p<0.05\right)$, but the BI group did not differ from the UC controls $\left(x^{2}=0.1\right)$. The vertical arrows mark the time-points of the six prevalence surveys.

in the SBI group, the annualised decline rates being $1.2 \%, 0.8 \%$, and $2.28 \%$ a year in the UC, BI, and SBI groups respectively.

\section{Discussion}

The purpose of this interim report was to see whether sustained intervention by GPs showed evidence at this early stage of a cumulative effect on reducing the prevalence of cigarette smoking among their patients. To demonstrate the efficacy of the intervention procedures it is necessary to show a greater decline in prevalence among the patients of the intervention practices (BI and SBI) than among the UC controls, who would be expected to reflect national trends and possible changes in GP intervention habits not connected with the study. It is clear that the brief intervention without clinic support (BI) had no measurable effect and the outcome did not differ from that in the UC controls. However, over the 30-month period studied so far, the supported intervention group (SBI) showed an estimated decline in selfreported smoking prevalence of $5.5 \%$ (from $36.4 \%$ to $30.9 \%$ ) which was almost double that estimated for the UC controls, the difference being statistically significant $(p<0.025)$. These results are consistent with those of a prospective study which followed cohorts of patients from these practice groups for one year after the start of intervention and found that the proportion who stopped smoking was increased by the SBI procedure but not by BI. ${ }^{4}$

Although the statistical analysis adjusted for practice effects and for age and other demographic variables, the SBI practices were self-selected and the possibility cannot be excluded that some unidentified influence related to this was responsible for the enhanced reduction in smoking prevalence among 
their patients. However, this group comprised one third of the practices approached, and a prospective study in the same practices, which included within practice controls, showed that the SBI intervention had a specific effect. ${ }^{4}$ Furthermore, when these practices were providing their usual care (with an initial cohort of smokers before the main study) the results were similar to those of the other practices. ${ }^{4}$ This suggests that the SBI procedure was probably responsible for the reduction in smoking prevalence observed in the present study.

This study and the initial prospective component ${ }^{4}$ is the first phase of an ongoing programme. The input so far has been limited to GP intervention, and the effect on smoking prevalence has been monitored for less than three years, which is a relatively short time to produce a detectable effect on prevalence. For example, the Minnesota Heart Health Program (MHHP), a well-known, large-scale research and demonstration project of population-wide primary prevention of cardiovascular disease, is scheduled to run for ten years and aims to achieve a reduction in multiple risk factors including cigarette smoking in intervention versus control communities. ${ }^{10}$ In a report of progress after the first three years of the MHHP evaluation of the smoking component was limited to assessment of exposure to and awareness of the anti-smoking activities rather than the effect on smoking behaviour or prevalence which will be assessed at a later stage. ${ }^{10}$

It is possible that over the next few years our programme will show larger effects on prevalence. We have learnt so far that the SBI procedure is more effective than BI and, as part of the second phase, the remaining Camberwell practices have agreed to adopt it. We have also learnt how the SBI procedure might be improved. ${ }^{4}$ We have recently introduced a brief intervention for health visitors in the Camberwell District and plan in the future to involve pharmacists also. The Hammersmith practices will remain as controls. If the results at the end of phase 2 are encouraging, it will then become necessary to validate the extent to which samples of patients attending GPs' surgeries are representative of all the patients on the practice lists and to estimate the reliability of selfreports with a biochemical measure.
In conclusion, our results provide encouraging evidence that brief intervention by GPs with support and back-up from a smokers' clinic can, when sustained on a continuous basis, reach sufficient numbers of smokers to reduce the prevalence of smoking in their practice populations.

This programme is funded mainly by long term support from the Department of Health and Social Security, but the staff responsible for the design and analysis are supported by the Medical Research Council, and we thank both these sources of support. We also thank Wilhemina Boyle for secretarial help. Above all, we thank all the general practitioners and their receptionists for tolerating our interference and the addition to their workload which participation inevitably involved.

\section{References}

${ }^{1}$ Russell MAH, Wilson C, Taylor C, Baker CD. Effect of general practitioners' advice against smoking. $\mathrm{Br}$ Med J 1979; 2: 231-5.

2 Jamrozik K, Vessey M, Fowler G, Wald N, Parker G, Van Vunakis $H$. Controlled trial of three different antismoking interventions in general practice. $\mathrm{Br}$ Med $\mathrm{J}$ 1984; 288: 1499-503.

${ }^{3}$ Russell MAH, Merriman R, Stapleton J, Taylor W. Effect of nicotine chewing gum as an adjunct to general practitioners' advice against smoking. $\mathrm{Br}$ Med J 1983; 287: 1782-5.

${ }^{4}$ Russell MAH, Stapleton JA, Jackson PH, Hajek P, Belcher M. District programme to reduce smoking: Effect of clinic supported brief intervention by general practitioners. Br Med J 1987; 295: 1240-4.

${ }^{5}$ Fagerstrom K. Effects of nicotine chewing gum and follow-up appointments in physician-based smoking cessation. Prev Med 1984; 13: 517-27.

${ }^{6}$ Richmond RL, Austin A, Webster IW. Three year evaluation of a programme by general practioners to help patients to stop smoking. $\mathrm{Br}$ Med J 1986; 292: 803-6.

${ }^{7}$ Baker PJ, Nelder JA. The GLIM system, release 3. Oxford: Numerical Algorithms Groups, 1978.

${ }^{8}$ Harrell FE. The LOGIST procedure, in "SUGI Supplementary Library Users Guide", Cary, North Carolina: SAS Institute Inc, 1983.

9 Office of Population Censuses and Surveys. General household survey 1984. London: HMSO, 1986.

${ }^{10}$ Mittelmark MB, Luepker RV, Jacobs DR, et al. Community-wide prevention of cardiovascular disease: Education strategies of the Minnesota Heart Health Program. Prev Med 1986; 15: 1-17.

Accepted for publication February 1988 